\title{
Phaeohyphomycosis Caused by Phaeoacremonium rubrigenum in an Immunosuppressive Patient: A Case Report and Review of the Literature
}

\author{
Sadanori Furudate ${ }^{a, b}$ Shu Sasai ${ }^{a}$ Yukikazu Numata ${ }^{a}$ \\ Taku Fujimura $^{\mathrm{b}}$ Setsuya Aiba ${ }^{\mathrm{b}}$ \\ ${ }^{a}$ Division of Dermatology, South Miyagi Medical Center, Ohgawara, and \\ ${ }^{\mathrm{b}}$ Department of Dermatology, Tohoku University Graduate School of Medicine, \\ Sendai, Japan
}

\section{Key Words}

Phaeohyphomycosis · Phaeoacremonium rubrigenum · Adult Still's disease

\begin{abstract}
Phaeohyphomycosis (PHM) is a rare, deep fungal infection of the skin and subcutaneous tissues caused by dematiaceous fungi. In this report, we describe a case of PHM caused by Phaeoacremonium rubrigenum, which is generally known to infect woody plants. We detected the gray-blackish villi by biopsy culture material, and slide culture revealed the conidia arising from slightly tapering phialides. Furthermore, we differentiated these fungi as P. rubrigenum by Basic Local Alignment Search Tool (BLAST) algorithm. We performed surgical debridement of disseminated nodules and administered oral itraconazole for a duration of 4 weeks. One year after stopping itraconazole, there was no sign of relapsing subcutaneous nodules. To our knowledge, this is the third case report of PHM developing from skin infection by $P$. rubrigenum in human.
\end{abstract}

\section{Introduction}

Generally, dematiaceous fungal infections have been categorized into three groups: chromoblastomycosis (CBM), phaeohyphomycosis (PHM), and mycetomas, depending on the characteristic appearance of the pathogens in the infected tissue [1]. More than $80 \%$ of these fungal infections are CBM, which usually affect the extremities and have the histological finding of sclerotic cell formation [1]. On the other hand, PHM is 
histologically characterized by colored hyphae and spores, thereby distinguishing it from other dematiaceous fungal infections.

PHM is a rare deep fungal infection of the skin and subcutaneous tissues caused by dematiaceous fungi. Most cases are caused by Exophiala jeanselmei, followed in frequency by Phialophora spp and Cladosporium spp. The majority of cases of PHM are thought to be in immunocompromised hosts [1]. There are only two cases of PHM caused by Phaeoacremonium rubrigenum in the English literature [2, 3]. In this report, we present a third case of PHM that developed in a patient with adult Still's disease caused by $P$. rubrigenum.

\section{Case Report}

A 76-year-old woman consulted our outpatient clinic for a three-month history of multiple, proliferating subcutaneous nodules on her right leg. She had suffered from adult Still's disease for three years and had been treated with oral prednisolone $15 \mathrm{mg} /$ day for two years. On her first visit, physical examination revealed multiple subcutaneous abscesses, 10 to $30 \mathrm{~mm}$ in size, disseminated on the right leg, some of which were ulcerated (fig. 1). Laboratory data at the examination showed high serum levels of $\beta$-D glucan ( $94 \mathrm{pg} / \mathrm{ml}$, normal range less than $20 \mathrm{pg} / \mathrm{ml}$ ). Biopsy from nodules revealed dense infiltration of histiocytes, neutrophils and multinucleated giant cells. The dematiaceous fungi can be identified in the dermis and subcutaneous tissues (fig. 2a). In addition, Grocott staining of the biopsy specimen demonstrated numerous hyphae throughout the lesions (fig. 2b). Cultures on Potato Dextrose Agar (PDA) detected the gray-blackish villi on the obverse side (fig. 2c). Additionally, slide culture performed for one week at $25^{\circ} \mathrm{C}$ revealed conidia arising from slightly tapering phialides (fig. 2d). Furthermore, we extracted DNA from this cultured villi and submitted its sequence to the GenBank Basic Local Alignment Search Tool (BLAST) research and identified the infection of $P$. rubrigenum (fig. 3 ). From the above data, we diagnosed this patient as having PHM. We performed surgical debridement of the disseminated nodules and administered oral itraconazole (ITCZ) $400 \mathrm{mg}$ once every week for 3 months. One year after stopping ITCZ, there was no sign of relapsing subcutaneous nodules.

\section{Discussion}

We describe a case of PHM forming multiple abscesses on the legs in a Japanese woman, in which we genetically detected $P$. rubrigenum from a skin abscess. Since this fungus commonly infects woody plants such as grapevines, to our knowledge, this is the third case report of $P$. rubrigenum affecting the human skin.

Dematiaceous fungi, also called pigmented fungi, contain melanin-like pigment in the cell walls that arise from gray-blackish villi on the culture medium, and can cause a variety of infections in human known as PHM [1]. Taxonomically, PHM includes various deuteromycetes. Generally, dematiaceous fungi form muriform or sclerotic cells in healthy donors, but in immunosuppressed donors, these specific forms do not necessarily develop [1]. CBM, deriving from dematiaceous fungi, is known to mainly arise in healthy donors. In contrast, PHM mainly develops in immunocompromised hosts (e.g. malignant tumor, autoimmune disease). In the present case, since the patient had been administered oral steroid for adult Still's disease for two years, her immune system might have been suppressed, with the result that the fungi formed typical hyphae. 
At present, 29 species of Phaeoacremonium have been reported [4], three of which are associated with PHM (table 1) [2, 3, 5-16]. To our knowledge, it is extremely rare for $P$. rubrigenum to be detected in human organ cultures [2,3].P. rubrigenum typically appears as light purple-pink to brown colonies, with conidiophores that are mostly short and unbranched in slide cultures [4]. In humans infected with Phaeoacremonium, cutaneous or subcutaneous lesions are the most common, but there have been reported cases of central nervous system involvement [5], onychomycosis [6], endophthalmitis [7], endocarditis [8] and disseminated disease (fungemia) [9] (table 1).

In the present case, the patient underwent surgical resection of the subcutaneous abscesses followed by administration of oral ITCZ $400 \mathrm{mg}$ once every week for 3 months. Previously, Ogawa et al. [19] reported the treatment for PHM by antifungal reagent (ITCZ, terbinafine, fluconazole or amphotericin B with ITCZ) after surgical resection. Interestingly, they selected ITCZ for $11 / 17$ cases. In addition, the administration of ITCZ is permitted in Japan in two different ways: (1) $400 \mathrm{mg}$ once every week for 3 months, and (2) 100 200 mg every day. It was recently reported that the recurrence rate of PHM under a conventional dose of ITCZ was about $66 \%(4 / 6)[2$, $3,9,10,17]$. In contrast, it was reported that there was no recurrence of PHM after the administration of $400 \mathrm{mg}$ of ITCZ, though the report described only one case treated with ITCZ pulse therapy for PHM [18]. Therefore, in the present case, we selected highdose ITCZ therapy and there is no sign of local recurrence of PHM one year after the therapy.

Table 1. Reported cases of human mycotic infections due to Phaeoacremonium species

\begin{tabular}{llllll}
\hline Case No. & Age of onset & Sex & Distribution of lesions & Species of fungi & Ref. \\
\hline 1 & 61 years & female & left foot & Phaeoacremonium rubrigenum & 2 \\
2 & 55 years & male & left ankle and foot & Phaeoacremonium rubrigenum & 3 \\
3 & 24 years & male & brain & Phaeoacremonium parasiticum & 5 \\
4 & (middle-aged) & male & foot nail & Phaeoacremonium parasiticum & 6 \\
5 & (adult) & male & eye & Phaeoacremonium parasiticum & 7 \\
6 & 45 years & male & endocardium & Phaeoacremonium parasiticum & 8 \\
7 & 31 years & female & blood (fungemia) & Phaeoacremonium parasiticum & 9 \\
8 & 40 years & male & left forearm, right buttock & Phaeoacremonium parasiticum & 9 \\
9 & 26 years & female & left forearm & Phaeoacremonium parasiticum & 10 \\
10 & 59 years & female & right knee & Phaeoacremonium parasiticum & 11 \\
11 & (adult) & male & forefinger & Phaeoacremonium parasiticum & 12 \\
12 & 49 years & male & left foot & Phaeoacremonium parasiticum & 13 \\
13 & 45 years & male & arm & Phaeoacremonium parasiticum & 14 \\
14 & 14 months & male & blood (fungemia) & Phaeoacremonium inflatipes & 15 \\
15 & 83 years & female & left knee & Phaeoacremonium inflatipes & 16 \\
\hline Present & 76 years & female & right leg & Phaeoacremonium rubrigenum & \\
case & & & & & \\
\hline
\end{tabular}




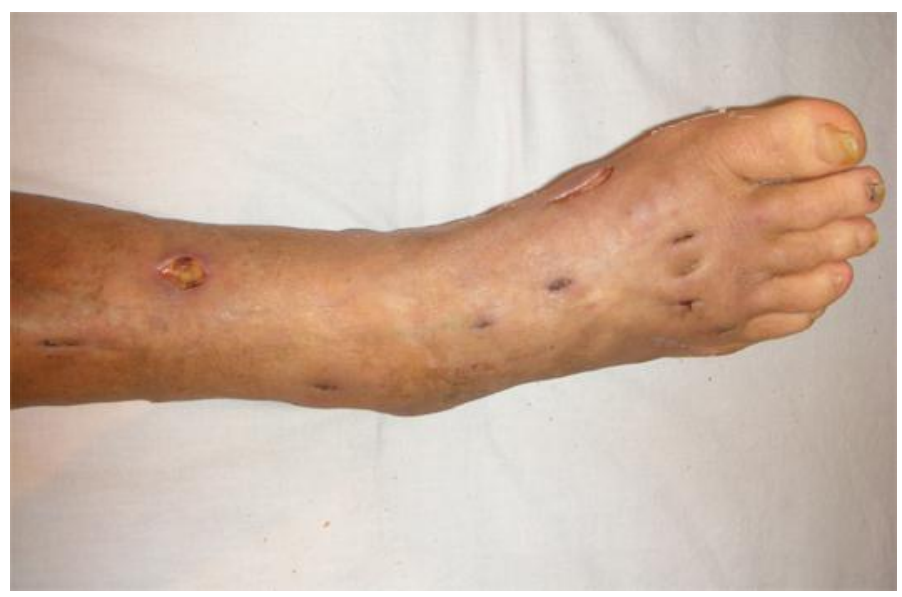

Fig. 1. Multiple subcutaneous abscesses, 10 to $30 \mathrm{~mm}$ in size, on the right leg.
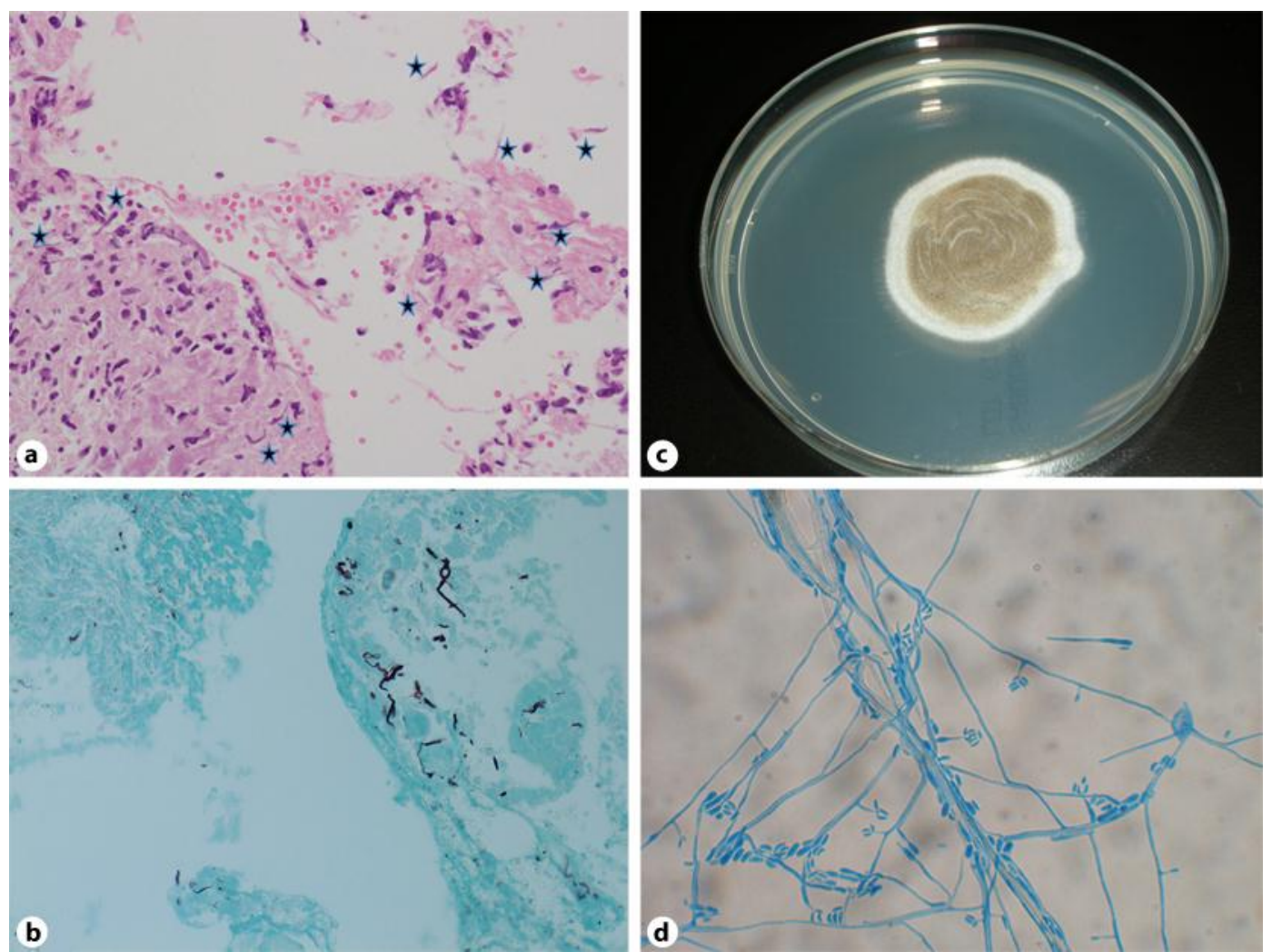

Fig. 2. The dematiaceous fungi can be identified in the dermis and subcutaneous tissues (a). Grocott staining specimen revealed blackish hyphae throughout the nodules (b). The biopsy material was cultured on Potato Dextrose Agar (PDA) and the gray-blackish villi appeared on the obverse side (c). Slide culture for one week at $25^{\circ} \mathrm{C}$. The conidia arising from slightly tapering phialides (d).

Hematoxilin and eosin: original magnification $\times 200$ (a), Grocott staining, original magnification $\times 200$ (b). 
- $Q u e r y=6917$ ITS (559 bp)

- Database: /b/DNA.DATA/ddbjpln1-7.seq;

/b/DDBJNEW.DATA/new_ddbjpln.seq

- Sequences producing significant alignments:

(bits)

AB278173.1 Phaeoacremonium rubrigenum gene for 18S rRNA... 1076

AF197989.1 Phaeoacremonium rubrigenum strain CBS 729.97... 1061

AF118139.1 Phaeoacremonium rubrigenum 18S ribosomal RNA... 1053

AF197988.1 Phaeoacremonium rubrigenum strain CBS 498.97 ... 1041

GU355672.1 Phaeoacremonium rubrigenum isolate HNAS13 in... $\underline{1029}$

GU355669.1 Phaeoacremonium rubrigenum isolate HNAS10 in... $\underline{1029}$

Fig. 3. Genetic analysis by Basic Local Alignment Search Tool (BLAST) research.

\section{References}

1 Ishida T, Aota N, Fukuda T: Chromomycosis associated with myelodysplastic syndrome caused by Exophiala jeanselmei: a review of reported cases of dematiaceous fungal infection in Japan for the recent 10 years. Jpn J Dermatol 2009;119:1069-1077.

-2 Matsui T, Nishimoto K, Udagawa S, Ishihara H, Ono T: Subcutaneous phaeohyphomycosis caused by Phaeoacremonium rubrigenum in an immunosuppressed patient. J Nihon Ishinkin Gakkai Zasshi 1999;40:99-102.

-3 Guarro J, Alves SH, Gené J, Grazziotin NA, Mazzuco R, Dalmagro C, Capilla J, Zaror L, Mayayo E: Two Cases of Subcutaneous Infection Due to Phaeoacremonium spp. J Clin Microbiol 2003;41:1332-1336.

-4 Essakhi S, Mugnai L, Crous PW, Groenewald JZ, Surico G: Molecular and phenotypic characterisation of novel Phaeoacremonium species isolated from esca diseased grapevines. Persoonia 2008;21:119-134.

5 McNeil CJ, Luo RF, Vogel H, Banaei N, Ho DY: Brain abscess caused by Phaeoacremonium parasiticum in an immunocompromised patient. J Clin Microbiol 2011;49:1171-1174.

$\checkmark 6$ Sun PL, Ju YM: Onychomycosis caused by Phaeoacremonium parasiticum: first case report. Mycoses 2011;54:172-174.

7 Huynh TK, Lee LR, Ellis D: Late-onset post-traumatic Phaeoacremonium parasiticum endophthalmitis. Clin Experiment Ophthalmol 2007;35:366-368.

8 Heath CH, Lendrum JL, Wetherall BL, Wesselingh SL, Gordon DL: Phaeoacremonium parasiticum infective endocarditis following liver transplantation. Clin Infect Dis 1997;25:1251-1252.

-9 Baddley JW, Mostert L, Summerbell RC, Moser SA: Phaeoacremonium parasiticum infections confirmed by beta-tubulin sequence analysis of case isolates. J Clin Microbiol 2006;44:2207-2211.

10 Baradkar VP, Mathur M, Kumar S: Phaeohyphomycosis of subcutaneous tissue caused by Phaeoacremonium parasiticum. Ind J Med Microbiol 2009;27:66-69.

$\checkmark 11$ Kitamura K, Mochizuki T, Ishizaki H, Fukushiro R: Phaeomycotic cyst caused by Phaeoacremonium parasiticum. Nihon Ishinkin Gakkai Zasshi 2000;41:89-95.

-12 Farina C, Gotti E, Mouniee D, Boiron P, Goglio A: Phaeoacremonium parasiticum cutaneous infection in a kidney-transplanted patient successfully treated by surgery. Transpl Infect Dis 2007;9:253-255.

-13 Marques SA, Camargo RM, Summerbell RC, De Hoog GS, Ishioka P, Chambo-Cordaro LM, Marques ME: Subcutaneous phaeohyphomycosis caused by Phaeoacremonium parasiticum in a renal transplanted patient. Med Mycol 2006;44:671-676.

14 Ajello L, Georg LK, Steigbigel RT, Wang CJ: A case of phaeohyphomycosis caused by a new species of Phialophora. Mycologia 1974;66:490-498.

15 Wang SC, Hsueh PR, Liaw SJ, Chang LY, Lu CY, Jou ST, Huang LM: Fatal fungemia due to Phaeoacremonium inflatipes in a child with severe aplastic anemia. Clin Infect Dis 2005;40:1067-1068.

16 Padhye AA, Davis MS, Baer D, Reddick A, Sinha KK, Ott J: Phaeohyphomycosis caused by Phaeoacremonium inflatipes. J Clin Microbiol 1998;36:2763-2765. 
17 Beaudreuil S, Buchler M, Al Najjar A, Bastides F, Francois M, Duong TH, Nivet H, Richard-Lenoble D, Lebranchu Y: Acute septic arthritis after kidney transplantation due to Acremonium. Nephrol Dial Transplant 2003;18:850-851.

-18 Palencarova E, Jesenska Z, Plank L, Straka S, Baska T, Hajtman A, Pec J: Phaeohyphomycosis caused by Alternaria species and Phaeosclera dematioides Sigler, Tsuneda and Carmichael. Clin Exp Dermatol 1995;20:419-422.

19 Ogawa MM, Galante NZ, Godoy P, Fischman-Gompertz O, Martelli F, Colombo AL, Tomimori J, MedinaPestana JO: Treatment of subcutaneous phaeohyphomycosis and prospective follow-up of 17 kidney transplant recipients. J Am Acad Dermatol 2009;61:977-985. 